Research Article

\title{
Strong Convergence Theorems of Viscosity Iterative Methods for a Countable Family of Strict Pseudo-contractions in Banach Spaces
}

\author{
Rabian Wangkeeree and Uthai Kamraksa \\ Department of Mathematics, Faculty of Science, Naresuan University, Phitsanulok 65000, Thailand \\ Correspondence should be addressed to Rabian Wangkeeree, rabianw@nu.ac.th
}

Received 23 June 2010; Accepted 13 August 2010

Academic Editor: A. T. M. Lau

Copyright (c) 2010 R. Wangkeeree and U. Kamraksa. This is an open access article distributed under the Creative Commons Attribution License, which permits unrestricted use, distribution, and reproduction in any medium, provided the original work is properly cited.

For a countable family $\left\{T_{n}\right\}_{n=1}^{\infty}$ of strictly pseudo-contractions, a strong convergence of viscosity iteration is shown in order to find a common fixed point of $\left\{T_{n}\right\}_{n=1}^{\infty}$ in either a $p$-uniformly convex Banach space which admits a weakly continuous duality mapping or a $p$-uniformly convex Banach space with uniformly Gâteaux differentiable norm. As applications, at the end of the paper we apply our results to the problem of finding a zero of accretive operators. The main result extends various results existing in the current literature.

\section{Introduction}

Let $E$ be a real Banach space and $C$ a nonempty closed convex subset of $E$. A mapping $f: C \rightarrow$ $C$ is called $k$-contraction if there exists a constant $0<k<1$ such that $\|f(x)-f(y)\| \leq k\|x-y\|$ for all $x, y \in C$. We use $\prod_{C}$ to denote the collection of all contractions on $C$. That is, $\prod_{C}=\{f$ : $f$ is a contraction on $C$ \}. A mapping $T: C \rightarrow C$ is said to be $\lambda$-strictly pseudo-contractive mapping (see, e.g., [1]) if there exists a constant $0 \leq \lambda<1$, such that

$$
\|T x-T y\|^{2} \leq\|x-y\|^{2}+\lambda\|(I-T) x-(I-T) y\|^{2},
$$

for all $x, y \in C$. Note that the class of $\lambda$-strict pseudo-contractions strictly includes the class of nonexpansive mappings which are mapping $T$ on $C$ such that $\|T x-T y\| \leq\|x-y\|$, for all $x$, $y \in C$. That is, $T$ is nonexpansive if and only if $T$ is a 0 -strict pseudo-contraction. A mapping 
$T: C \rightarrow C$ is said to be $\lambda$-strictly pseudo-contractive mapping with respect to $p$ if, for all $x$, $y \in C$, there exists a constant $0 \leq \lambda<1$ such that

$$
\|T x-T y\|^{p} \leq\|x-y\|^{p}+\lambda\|(I-T) x-(I-T) y\|^{p} .
$$

A countable family of mapping $\left\{T_{n}: C \rightarrow C\right\}_{i=1}^{\infty}$ is called a family of uniformly $\lambda$-strict pseudo-contractions with respect to $p$, if there exists a constant $\lambda \in[0,1)$ such that

$$
\left\|T_{n} x-T_{n} y\right\|^{p} \leq\|x-y\|^{p}+\lambda\left\|\left(I-T_{n}\right) x-\left(I-T_{n}\right) y\right\|^{p}, \quad \forall x, y \in C, \forall n \geq 1 .
$$

We denote by $F(T)$ the set of fixed points of $T$, that is, $F(T)=\{x \in C: T x=x\}$.

In order to find a fixed point of nonexpansive mapping $T$, Halpern [2] was the first to introduce the following iteration scheme which was referred to as Halpern iteration in a Hilbert space: $u, x_{1} \in C,\left\{\alpha_{n}\right\} \subset[0,1]$,

$$
x_{n+1}=\alpha_{n} x+\left(1-\alpha_{n}\right) T x_{n}, \quad n \geq 1 .
$$

He pointed out that the control conditions (C1) $\lim _{n \rightarrow \infty} \alpha_{n}=0$ and (C2) $\sum_{n=1}^{\infty}=\infty$ are necessary for the convergence of the iteration scheme (1.4) to a fixed point of $T$. Furthermore, the modified version of Halpern iteration was investigated widely by many mathematicians. Recently, for the sequence of nonexpansive mappings $\left\{T_{n}\right\}_{n=1}^{\infty}$ with some special conditions, Aoyama et al. [3] introduced a Halpern type iterative sequence for finding a common fixed point of a countable family of nonexpansive mappings $\left\{T_{n}: C \rightarrow C\right\}$ satisfying some conditions. Let $x_{1}=x \in C$ and

$$
x_{n+1}=\alpha_{n} x+\left(1-\alpha_{n}\right) T_{n} x_{n}
$$

for all $n \in \mathbb{N}$, where $C$ is a nonempty closed convex subset of a uniformly convex Banach space $E$ whose norm is uniformly Gâteaux differentiable, and $\left\{\alpha_{n}\right\}$ is a sequence in $[0,1]$. They proved that $\left\{x_{n}\right\}$ defined by (1.5) converges strongly to a common fixed point of $\left\{T_{n}\right\}$. Very recently, Song and Zheng [4] also studied the strong convergence theorem of Halpern iteration (1.5) for a countable family of nonexpansive mappings $\left\{T_{n}: C \rightarrow C\right\}$ satisfying some conditions in either a reflexive and strictly convex Banach space with a uniformly Gâteaux differentiable norm or a reflexive Banach space $E$ with a weakly continuous duality mapping. Other investigations of approximating common fixed points for a countable family of nonexpansive mappings can be found in $[3,5-10]$ and many results not cited here.

On the other hand, in the last twenty years or so, there are many papers in the literature dealing with the iteration approximating fixed points of Lipschitz strongly pseudocontractive mappings by using the Mann and Ishikawa iteration process. Results which had been known only for Hilbert spaces and Lipschitz mappings have been extended to more general Banach spaces and a more general class of mappings (see, e.g., [1, 11-13] and the references therein). 
In 2007, Marino and Xu [12] proved that the Mann iterative sequence converges weakly to a fixed point of $\lambda$-strict pseudo-contractions in Hilbert spaces, which extend Reich's theorem [14, Theorem 2] from nonexpansive mappings to $\lambda$-strict pseudo-contractions in Hilbert spaces.

Recently, Zhou [13] obtained some weak and strong convergence theorems for $\lambda$ strict pseudo-contractions in Hilbert spaces by using Mann iteration and modified Ishikawa iteration which extend Marino and Xu's convergence theorems [12].

More recently, Hu and Wang [11] obtained that the Mann iterative sequence converges weakly to a fixed point of $\lambda$-strict pseudo-contractions with respect to $p$ in $p$-uniformly convex Banach spaces. To be more precise, they obtained the following theorem.

\section{Theorem HW}

Let $E$ be a real $p$-uniformly convex Banach space which satisfies one of the following:

(i) $E$ has a Fréchet differentiable norm;

(ii) E satisfies Opial's property.

Let $C$ a nonempty closed convex subset of $E$. Let $T: C \rightarrow C$ be a $\lambda$-strict pseudo-contractions with respect to $p, \lambda \in\left[0, \min \left\{1,2^{-(p-2)} c_{p}\right\}\right)$ and $F(T) \neq \emptyset$. Assume that a real sequence $\left\{\alpha_{n}\right\}$ in $(0,1)$ satisfy the following conditions:

$$
0<\varepsilon \leq \alpha_{n} \leq 1-\varepsilon<1-\frac{2^{p-2} \lambda}{c_{p}}, \quad \forall n \geq 1 .
$$

Then Mann iterative sequence $\left\{x_{n}\right\}$ defined by

$$
\begin{gathered}
x_{1}=x \in C, \\
x_{n+1}=\alpha_{n} x_{n}+\left(1-\alpha_{n}\right) T x_{n}, \quad n \geq 1,
\end{gathered}
$$

converges weakly to a fixed point of $T$.

Very recently, $\mathrm{Hu}$ [15] obtained strong convergence theorems on a mixed iteration scheme by the viscosity approximation methods for $\lambda$-strict pseudo-contractions in $p$ uniformly convex Banach spaces with uniformly Gâteaux differentiable norm. To be more precise, $\mathrm{Hu}[15]$ obtained the following theorem.

Theorem H. Let $E$ be a real p-uniformly convex Banach space with uniformly Gateaux differentiable norm, and $C$ a nonempty closed convex subset of $E$ which has the fixed point property for nonexpansive mappings. Let $T: C \rightarrow C$ be a $\lambda$-strict pseudo-contractions with respect to $p$, $\lambda \in\left[0, \min \left\{1,2^{-(p-2)} C_{p}\right\}\right)$ and $F(T) \neq \emptyset$. Let $f: C \rightarrow C$ be a $k$-contraction with $k \in(0,1)$. Assume that real sequences $\left\{\alpha_{n}\right\},\left\{\beta_{n}\right\}$ and $\left\{\gamma_{n}\right\}$ in $(0,1)$ satisfy the following conditions:

(i) $\alpha_{n}+\beta_{n}+\gamma_{n}=1$ for all $n \in \mathbb{N}$,

(ii) $\lim _{n \rightarrow \infty} \alpha_{n}=0$ and $\sum_{n=0}^{\infty} \alpha_{n}=+\infty$,

(iii) $0<\lim _{\inf _{n \rightarrow \infty}} \gamma_{n} \leq \lim \sup _{n \rightarrow \infty} \gamma_{n}<\xi$, where $\xi=1-2^{p-2} \lambda c_{p}^{-1}$. 
Let $\left\{x_{n}\right\}$ be the sequence generated by the following:

$$
\begin{gathered}
x_{1}=x \in C, \\
x_{n+1}=\alpha_{n} f\left(x_{n}\right)+\beta_{n} x_{n}+\gamma_{n} T x_{n}, \quad n \geq 1 .
\end{gathered}
$$

Then the sequence $\left\{x_{n}\right\}$ converges strongly to a fixed point of $T$.

In this paper, motivated by $\mathrm{Hu}$ and Wang [11], $\mathrm{Hu}$ [15], Aoyama et al. [3] and Song and Zheng [4], we introduce a viscosity iterative approximation method for finding a common fixed point of a countable family of strictly pseudo-contractions which is a unique solution of some variational inequality. We prove the strong convergence theorems of such iterative scheme in either $p$-uniformly convex Banach space which admits a weakly continuous duality mapping or $p$-uniformly convex Banach space with uniformly Gâteaux differentiable norm. As applications, at the end of the paper, we apply our results to the problem of finding a zero of an accretive operator. The results presented in this paper improve and extend the corresponding results announced by $\mathrm{Hu}$ and Wang [11], $\mathrm{Hu}$ [15], Aoyama et al. [3] Song and Zheng [4], and many others.

\section{Preliminaries}

Throughout this paper, let $E$ be a real Banach space and $E^{*}$ its dual space. We write $x_{n} \rightarrow x$ (resp., $x_{n}-^{*} x$ ) to indicate that the sequence $\left\{x_{n}\right\}$ weakly (resp., weak*) converges to $x$; as usual $x_{n} \rightarrow x$ will symbolize strong convergence. Let $S(E)=\{x \in E:\|x\|=1\}$ denote the unit sphere of a Banach space $E$. A Banach space $E$ is said to have

(i) a Gateaux differentiable norm (we also say that $E$ is smooth), if the limit

$$
\lim _{t \rightarrow 0} \frac{\|x+t y\|-\|x\|}{t}
$$

exists for each $x, y \in S(E)$,

(ii) a uniformly Gateaux differentiable norm, if for each $y$ in $S(E)$, the limit (2.1) is uniformly attained for $x \in S(E)$,

(iii) a Fréchet differentiable norm, if for each $x \in S(E)$, the limit (2.1) is attained uniformly for $y \in S(E)$,

(iv) a uniformly Fréchet differentiable norm (we also say that $E$ is uniformly smooth), if the limit (2.1) is attained uniformly for $(x, y) \in S(E) \times S(E)$.

The modulus of convexity of $E$ is the function $\delta_{E}:[0,2] \rightarrow[0,1]$ defined by

$$
\delta_{E}(\epsilon)=\inf \left\{1-\left\|\frac{x+y}{2}\right\|:\|x\|=1,\|y\|=1,\|x-y\| \geq \epsilon\right\}, \quad 0 \leq \epsilon \leq 2
$$

$E$ is uniformly convex if and only if, for all $0<\epsilon \leq 2$ such that $\delta_{E}(\epsilon)>0$. $E$ is said to be $p$-uniformly convex, if there exists a constant $a>0$ such that $\delta_{E}(\epsilon) \geq a \epsilon^{p}$. 
The following facts are well known which can be found in $[16,17]$ :

(i) the normalized duality mapping $J$ in a Banach space $E$ with a uniformly Gâteaux differentiable norm is single-valued and strong-weak* uniformly continuous on any bounded subset of $E$;

(ii) each uniformly convex Banach space $E$ is reflexive and strictly convex and has fixed point property for nonexpansive self-mappings;

(iii) every uniformly smooth Banach space $E$ is a reflexive Banach space with a uniformly Gâteaux differentiable norm and has fixed point property for nonexpansive self-mappings.

Now we collect some useful lemmas for proving the convergence result of this paper.

Lemma 2.1 (see [11]). Let $E$ be a real p-uniformly convex Banach space and $C$ a nonempty closed convex subset of $E$. let $T: C \rightarrow C$ be a $\lambda$-strict pseudo-contraction with respect to $p$, and $\left\{\xi_{n}\right\}$ a real sequence in $[0,1]$. If $T_{n}: C \rightarrow C$ is defined by $T_{n} x:=\left(1-\xi_{n}\right) x+\xi_{n} T x$, for all $x \in C$, then for all $x$, $y \in C$, the inequality holds

$$
\left\|T_{n} x-T_{n} y\right\|^{p} \leq\|x-y\|^{p}-\left(w_{p}\left(\xi_{n}\right) c_{p}-\xi_{n} \lambda\right)\|(I-T) x-(I-T) y\|^{p},
$$

where $c_{p}$ is a constant in $[18$, Theorem 1$]$. In addition, if $0 \leq \lambda<\min \left\{1,2^{-(p-2)} c_{p}\right\}, \xi=1-2^{p-2} \lambda c_{p}^{-1}$, and $\xi_{n} \in[0, \xi]$, then $\left\|T_{n} x-T_{n} y\right\| \leq\|x-y\|$, for all $x, y \in C$.

Lemma 2.2 (see $[19,20]$ ). Let $C$ be a nonempty closed convex subset of a Banach space $E$ which has uniformly Gâteaux differentiable norm, $T: C \rightarrow C$ a nonexpansive mapping with $F(T) \neq \emptyset$ and $f: C \rightarrow C$ a k-contraction. Assume that every nonempty closed convex bounded subset of $C$ has the fixed points property for nonexpansive mappings. Then there exists a continuous path: $t \rightarrow x_{t}$, $t \in(0,1)$ satisfying $x_{t}=t f\left(x_{t}\right)+(1-t) T x_{t}$, which converges to a fixed point of $T$ as $t \rightarrow 0^{+}$.

Lemma 2.3 (see [21]). Let $\left\{x_{n}\right\}$ and $\left\{y_{n}\right\}$ be bounded sequences in Banach space E such that

$$
x_{n+1}=\alpha_{n} x_{n}+\left(1-\alpha_{n}\right) y_{n}, \quad n \geq 0,
$$

where $\left\{\alpha_{n}\right\}$ is a sequence in $(0,1)$ such that $0<\lim _{\inf _{n \rightarrow \infty}} \alpha_{n} \leq \lim _{\sup _{n \rightarrow \infty}} \alpha_{n}<1$. Assume

$$
\limsup _{n \rightarrow \infty}\left(\left\|y_{n+1}-y_{n}\right\|-\left\|x_{n+1}-x_{n}\right\|\right) \leq 0
$$

Then $\lim _{n \rightarrow \infty}\left\|y_{n}-x_{n}\right\|=0$.

Definition 2.4 (see [3]). Let $\left\{T_{n}\right\}$ be a family of mappings from a subset $C$ of a Banach space $E$ into $E$ with $\bigcap_{n=1}^{\infty} F\left(T_{n}\right) \neq \emptyset$. We say that $\left\{T_{n}\right\}$ satisfies the AKTT-condition if for each bounded subset $B$ of $C$,

$$
\sum_{n=1}^{\infty} \sup _{z \in B}\left\|T_{n+1} z-T_{n} z\right\|<\infty
$$


Remark 2.5. The example of the sequence of mappings $\left\{T_{n}\right\}$ satisfying AKTT-condition is supported by Lemma 4.1.

Lemma 2.6 (see [3, Lemma 3.2]). Suppose that $\left\{T_{n}\right\}$ satisfies AKTT-condition. Then, for each $y \in$ $C,\left\{T_{n} y\right\}$ converses strongly to a point in $C$. Moreover, let the mapping $T$ be defined by

$$
T y=\lim _{n \rightarrow \infty} T_{n} y, \quad \forall y \in C .
$$

Then for each bounded subset $B$ of $C, \lim _{n \rightarrow \infty} \sup _{z \in B}\left\|T z-T_{n} z\right\|=0$.

Lemma 2.7 (see [22]). Assume that $\left\{\alpha_{n}\right\}$ is a sequence of nonnegative real numbers such that

$$
\alpha_{n+1} \leq\left(1-\gamma_{n}\right) \alpha_{n}+\delta_{n}
$$

where $\left\{\gamma_{n}\right\}$ is a sequence in $(0,1)$ and $\left\{\delta_{n}\right\}$ is a sequence such that

(a) $\sum_{n=1}^{\infty} \gamma_{n}=\infty$;

(b) $\lim \sup _{n \rightarrow \infty} \delta_{n} / \gamma_{n} \leq 0$ or $\sum_{n=1}^{\infty}\left|\delta_{n}\right|<\infty$.

Then $\lim _{n \rightarrow \infty} \alpha_{n}=0$.

By a gauge function $\varphi$ we mean a continuous strictly increasing function $\varphi:[0, \infty) \rightarrow$ $[0, \infty)$ such that $\varphi(0)=0$ and $\varphi(t) \rightarrow \infty$ as $t \rightarrow \infty$. Let $E^{*}$ be the dual space of $E$. The duality mapping $J_{\varphi}: E \rightarrow 2^{E^{*}}$ associated to a gauge function $\varphi$ is defined by

$$
J_{\varphi}(x)=\left\{f^{*} \in E^{*}:\left\langle x, f^{*}\right\rangle=\|x\| \varphi(\|x\|),\left\|f^{*}\right\|=\varphi(\|x\|)\right\}, \quad \forall x \in E .
$$

In particular, the duality mapping with the gauge function $\varphi(t)=t$, denoted by $J$, is referred to as the normalized duality mapping. Clearly, there holds the relation $J_{\varphi}(x)=$ $(\varphi(\|x\|) /\|x\|) J(x)$ for all $x \neq 0$ (see [23]). Browder [23] initiated the study of certain classes of nonlinear operators by means of the duality mapping $J_{\varphi}$. Following Browder [23], we say that a Banach space $E$ has a weakly continuous duality mapping if there exists a gauge $\varphi$ for which the duality mapping $J_{\varphi}(x)$ is single-valued and continuous from the weak topology to the weak* topology, that is, for any $\left\{x_{n}\right\}$ with $x_{n} \rightarrow x$, the sequence $\left\{J_{\varphi}\left(x_{n}\right)\right\}$ converges weakly* to $J_{\varphi}(x)$. It is known that $l^{p}$ has a weakly continuous duality mapping with a gauge function $\varphi(t)=t^{p-1}$ for all $1<p<\infty$. Set

$$
\Phi(t)=\int_{0}^{t} \varphi(\tau) d \tau, \quad \forall t \geq 0
$$

then

$$
J_{\varphi}(x)=\partial \Phi(\|x\|), \quad \forall x \in E,
$$

where $\partial$ denotes the subdifferential in the sense of convex analysis (recall that the subdifferential of the convex function $\phi: E \rightarrow \mathbb{R}$ at $x \in E$ is the set $\partial \phi(x)=\left\{x^{*} \in E^{*} ; \phi(y) \geq\right.$ $\phi(x)+\left\langle x^{*}, y-x\right\rangle$, for all $\left.\left.y \in E\right\}\right)$. 
The following lemma is an immediate consequence of the subdifferential inequality. The first part of the next lemma is an immediate consequence of the subdifferential inequality and the proof of the second part can be found in [24].

Lemma 2.8 (see [24]). Assume that a Banach space E has a weakly continuous duality mapping $J_{\varphi}$ with gauge $\varphi$.

(i) For all $x, y \in E$, the following inequality holds:

$$
\Phi(\|x+y\|) \leq \Phi(\|x\|)+\left\langle y, J_{\varphi}(x+y)\right\rangle .
$$

In particular, in a smooth Banach space $E$, for all $x, y \in E$,

$$
\|x+y\|^{2} \leq\|x\|^{2}+2\langle y, J(x+y)\rangle \text {. }
$$

(ii) Assume that a sequence $\left\{x_{n}\right\}$ in E converges weakly to a point $x \in E$.

Then the following identity holds:

$$
\limsup _{n \rightarrow \infty} \Phi\left(\left\|x_{n}-y\right\|\right)=\limsup _{n \rightarrow \infty} \Phi\left(\left\|x_{n}-x\right\|\right)+\Phi(\|y-x\|), \quad \forall x, y \in E
$$

\section{Main Results}

For $T: C \rightarrow C$ a nonexpansive mapping, $t \in(0,1)$ and $f \in \prod_{C}, t f+(1-t) T: C \rightarrow C$ defines a contraction mapping. Thus, by the Banach contraction mapping principle, there exists a unique fixed point $x_{t}^{f}$ satisfying

$$
x_{t}^{f}=t f\left(x_{t}\right)+(1-t) T x_{t}^{f} .
$$

For simplicity we will write $x_{t}$ for $x_{t}^{f}$ provided no confusion occurs. Next, we will prove the following lemma.

Lemma 3.1. Let $E$ be a reflexive Banach space which admits a weakly continuous duality mapping $J_{\varphi}$ with gauge $\varphi$. Let $C$ be a nonempty closed convex subset of $E, T: C \rightarrow C$ a nonexpansive mapping with $F(T) \neq \emptyset$ and $f \in \prod_{C}$. Then the net $\left\{x_{t}\right\}$ defined by (3.1) converges strongly as $t \rightarrow 0$ to a fixed point $\tilde{x}$ of $T$ which solves the variational inequality:

$$
\left\langle(I-f) \tilde{x}, J_{\varphi}(\tilde{x}-z)\right\rangle \leq 0, \quad z \in F(T)
$$

Proof. We first show that the uniqueness of a solution of the variational inequality (3.2). Suppose both $\tilde{x} \in F(T)$ and $x^{*} \in F(T)$ are solutions to (3.2), then

$$
\begin{aligned}
& \left\langle(I-f) \tilde{x}, J_{\varphi}\left(\tilde{x}-x^{*}\right)\right\rangle \leq 0, \\
& \left\langle(I-f) x^{*}, J_{\varphi}\left(x^{*}-\tilde{x}\right)\right\rangle \leq 0 .
\end{aligned}
$$


Adding (3.3), we obtain

$$
\left\langle(I-f) \tilde{x}-(I-f) x^{*}, J_{\varphi}\left(\tilde{x}-x^{*}\right)\right\rangle \leq 0 .
$$

Noticing that for any $x, y \in E$,

$$
\begin{aligned}
\left\langle(I-f) x-(I-f) y, J_{\varphi}(x-y)\right\rangle & =\left\langle x-y, J_{\varphi}(x-y)\right\rangle-\left\langle f(x)-f(y), J_{\varphi}(x-y)\right\rangle \\
& \geq\|x-y\| \varphi(\|x-y\|)-\|f(x)-f(y)\| \varphi(\|x-y\|) \\
& \geq \Phi(\|x-y\|)-\alpha \Phi(\|x-y\|) \\
& =(1-\alpha) \Phi(\|x-y\|) \geq 0 .
\end{aligned}
$$

From (3.4), we conclude that $\Phi\left(\left\|\tilde{x}-x^{*}\right\|\right)=0$. This implies that $\tilde{x}=x^{*}$ and the uniqueness is proved. Below we use $\tilde{x}$ to denote the unique solution of (3.2). Next, we will prove that $\left\{x_{t}\right\}$ is bounded. Take a $p \in F(T)$; then we have

$$
\begin{aligned}
\left\|x_{t}-p\right\| & =\left\|t f\left(x_{t}\right)+(1-t) T x_{t}-p\right\| \\
& =\left\|(1-t) T x_{t}-(1-t) p+t\left(f\left(x_{t}\right)-p\right)\right\| \\
& \leq(1-t)\left\|x_{t}-p\right\|+t\left(\alpha\left\|x_{t}-p\right\|+\|f(p)-p\|\right) .
\end{aligned}
$$

It follows that

$$
\left\|x_{t}-p\right\| \leq \frac{1}{1-\alpha}\|f(p)-p\|
$$

Hence $\left\{x_{t}\right\}$ is bounded, so are $\left\{f\left(x_{t}\right)\right\}$ and $\left\{T\left(x_{t}\right)\right\}$. The definition of $\left\{x_{t}\right\}$ implies that

$$
\left\|x_{t}-T x_{t}\right\|=t\left\|f\left(x_{t}\right)-T x_{t}\right\| \longrightarrow 0, \quad \text { as } t \longrightarrow 0
$$

If follows from reflexivity of $E$ and the boundedness of sequence $\left\{x_{t}\right\}$ that there exists $\left\{x_{t_{n}}\right\}$ which is a subsequence of $\left\{x_{t}\right\}$ converging weakly to $w \in C$ as $n \rightarrow \infty$. Since $J_{\varphi}$ is weakly sequentially continuous, we have by Lemma 2.8 that

$$
\limsup _{n \rightarrow \infty} \Phi\left(\left\|x_{t_{n}}-x\right\|\right)=\limsup _{n \rightarrow \infty} \Phi\left(\left\|x_{t_{n}}-w\right\|\right)+\Phi(\|x-w\|), \quad \forall x \in E .
$$

Let

$$
H(x)=\limsup _{n \rightarrow \infty} \Phi\left(\left\|x_{t_{n}}-x\right\|\right), \quad \forall x \in E
$$

It follows that

$$
H(x)=H(w)+\Phi(\|x-w\|), \quad \forall x \in E
$$


Since

$$
\left\|x_{t_{n}}-T x_{t_{n}}\right\|=t_{n}\left\|f\left(x_{t_{n}}\right)-T x_{t_{n}}\right\| \longrightarrow 0, \quad \text { as } n \longrightarrow \infty,
$$

we obtain

$$
\begin{aligned}
H(T w) & =\limsup _{n \rightarrow \infty} \Phi\left(\left\|x_{t_{n}}-T w\right\|\right)=\limsup _{n \rightarrow \infty} \Phi\left(\left\|T x_{t_{n}}-T w\right\|\right) \\
& \leq \limsup _{n \rightarrow \infty} \Phi\left(\left\|x_{t_{n}}-w\right\|\right)=H(w) .
\end{aligned}
$$

On the other hand, however,

$$
H(T w)=H(w)+\Phi(\|T(w)-w\|)
$$

It follows from (3.13) and (3.14) that

$$
\Phi(\|T(w)-w\|)=H(T w)-H(w) \leq 0
$$

This implies that $T w=w$. Next we show that $x_{t_{n}} \rightarrow w$ as $n \rightarrow \infty$. In fact, since $\Phi(t)=$ $\int_{0}^{t} \varphi(\tau) d \tau$, for all $t \geq 0$, and $\varphi:[0, \infty) \rightarrow[0, \infty)$ is a gauge function, then for $1 \geq k \geq 0$, $\varphi(k x) \leq \varphi(x)$ and

$$
\Phi(k t)=\int_{0}^{k t} \varphi(\tau) d \tau=k \int_{0}^{t} \varphi(k x) d x \leq k \int_{0}^{t} \varphi(x) d x=k \Phi(t)
$$

Following Lemma 2.8, we have

$$
\begin{aligned}
\Phi\left(\left\|x_{t_{n}}-w\right\|\right)= & \Phi\left(\left\|\left(1-t_{n}\right) T x_{t_{n}}-\left(1-t_{n}\right) w+t_{n}\left(f\left(x_{t_{n}}\right)-w\right)\right\|\right) \\
= & \Phi\left(\left\|\left(1-t_{n}\right) T x_{t_{n}}-\left(1-t_{n}\right) w\right\|\right)+t_{n}\left\langle f\left(x_{t_{n}}\right)-w, J\left(x_{t_{n}}-w\right)\right\rangle \\
\leq & \Phi\left(\left(1-t_{n}\right)\left\|x_{t_{n}}-w\right\|\right)+t_{n}\left\langle f\left(x_{t_{n}}\right)-f(w), J\left(x_{t_{n}}-w\right)\right\rangle \\
& +t_{n}\left\langle f(w)-w, J\left(x_{t_{n}}-w\right)\right\rangle \\
\leq & \left(1-t_{n}\right) \Phi\left(\left\|x_{t_{n}}-w\right\|\right)+t_{n}\left\|f\left(x_{t_{n}}\right)-f(w)\right\|\left\|J\left(x_{t_{n}}-w\right)\right\| \\
& +t_{n}\left\langle f(w)-w, J\left(x_{t_{n}}-w\right)\right\rangle \\
\leq & \left(1-t_{n}\right) \Phi\left(\left\|x_{t_{n}}-w\right\|\right)+t_{n} \alpha\left\|x_{t_{n}}-w\right\|\left\|J_{\varphi}\left(x_{t_{n}}-w\right)\right\| \\
& +t_{n}\left\langle f(w)-w, J\left(x_{t_{n}}-w\right)\right\rangle \\
= & \left(1-t_{n}\right) \Phi\left(\left\|x_{t_{n}}-w\right\|\right)+t_{n} \alpha \Phi\left(\left\|x_{t_{n}}-w\right\|\right) \\
& +t_{n}\left\langle f(w)-w, J\left(x_{t_{n}}-w\right)\right\rangle \\
= & \left(1-t_{n}(1-\alpha)\right) \Phi\left(\left\|x_{t_{n}}-w\right\|\right)+t_{n}\left\langle f(w)-w, J\left(x_{t_{n}}-w\right)\right\rangle .
\end{aligned}
$$


This implies that

$$
\Phi\left(\left\|x_{t_{n}}-w\right\|\right) \leq \frac{1}{1-\alpha}\left\langle f(w)-w, J\left(x_{t_{n}}-w\right)\right\rangle
$$

Now observing that $x_{t_{n}} \rightarrow w$ implies $J_{\varphi}\left(x_{t_{n}}-w\right) \rightarrow 0$, we conclude from the last inequality that

$$
\Phi\left(\left\|x_{t_{n}}-w\right\|\right) \longrightarrow 0, \quad \text { as } n \longrightarrow \infty
$$

Hence $x_{t_{n}} \rightarrow w$ as $n \rightarrow \infty$. Next we prove that $w$ solves the variational inequality (3.2). For any $z \in F(T)$, we observe that

$$
\begin{aligned}
\left\langle(I-T) x_{t}-(I-T) z, J_{\varphi}\left(x_{t}-z\right)\right\rangle & =\left\langle x_{t}-z, J_{\varphi}\left(x_{t}-z\right)\right\rangle+\left\langle T x_{t}-T z, J_{\varphi}\left(x_{t}-z\right)\right\rangle \\
& =\Phi\left(\left\|x_{t}-z\right\|\right)-\left\langle T z-T x_{t}, J_{\varphi}\left(x_{t}-z\right)\right\rangle \\
& \geq \Phi\left(\left\|x_{t}-z\right\|\right)-\left\|T z-T x_{t}\right\|\left\|J_{\varphi}\left(x_{t}-z\right)\right\| \\
& \geq \Phi\left(\left\|x_{t}-z\right\|\right)-\left\|z-x_{t}\right\|\left\|J_{\varphi}\left(x_{t}-z\right)\right\| \\
& =\Phi\left(\left\|x_{t}-z\right\|\right)-\Phi\left(\left\|x_{t}-z\right\|\right)=0 .
\end{aligned}
$$

Since

$$
x_{t}=t f\left(x_{t}\right)+(1-t) T x_{t}
$$

we can derive that

$$
(I-f)\left(x_{t}\right)=-\frac{1}{t}(I-T) x_{t}+(I-T) x_{t}
$$

Thus

$$
\begin{aligned}
\left\langle(I-f)\left(x_{t}\right), J_{\varphi}\left(x_{t}-z\right)\right\rangle & =-\frac{1}{t}\left\langle(I-T) x_{t}-(I-T) z, J_{\varphi}\left(x_{t}-z\right)\right\rangle+\left\langle(I-T) x_{t}, J_{\varphi}\left(x_{t}-z\right)\right\rangle \\
& \leq\left\langle(I-T) x_{t}, J_{\varphi}\left(x_{t}-z\right)\right\rangle .
\end{aligned}
$$

Noticing that

$$
x_{t_{n}}-T x_{t_{n}} \longrightarrow w-T(w)=w-w=0
$$

Now replacing $t$ in (3.23) with $t_{n}$ and letting $n \rightarrow \infty$, we have

$$
\left\langle(I-f) w, J_{\varphi}(w-z)\right\rangle \leq 0 .
$$


So, $w \in F(T)$ is a solution of the variational inequality (3.2), and hence $w=\tilde{x}$ by the uniqueness. In a summary, we have shown that each cluster point of $\left\{x_{t}\right\}$ (at $t \rightarrow 0$ ) equals $\tilde{x}$. Therefore, $x_{t} \rightarrow \tilde{x}$ as $t \rightarrow 0$. This completes the proof.

Theorem 3.2. Let E be a real p-uniformly convex Banach space with a weakly continuous duality mapping $J_{\varphi}$, and $C$ a nonempty closed convex subset of $E$. Let $\left\{T_{n}: C \rightarrow C\right\}$ be a family of uniformly $\lambda$-strict pseudo-contractions with respect to $p, \lambda \in\left[0, \min \left\{1,2^{-(p-2)} c_{p}\right\}\right)$ and $\bigcap_{n=1}^{\infty} F\left(T_{n}\right) \neq \emptyset$. Let $f: C \rightarrow C$ be a $k$-contraction with $k \in(0,1)$. Assume that real sequences $\left\{\alpha_{n}\right\},\left\{\beta_{n}\right\}$ and $\left\{\gamma_{n}\right\}$ in $(0,1)$ satisfy the following conditions:

(i) $\alpha_{n}+\beta_{n}+\gamma_{n}=1$ for all $n \in \mathbb{N}$;

(ii) $\lim _{n \rightarrow \infty} \alpha_{n}=0$ and $\sum_{n=0}^{\infty} \alpha_{n}=+\infty$;

(iii) $0<\lim \inf _{n \rightarrow \infty} \gamma_{n} \leq \lim \sup _{n \rightarrow \infty} \gamma_{n}<\xi$, where $\xi=1-2^{p-2} \lambda c_{p}^{-1}$.

Let $\left\{x_{n}\right\}$ be the sequence generated by the following:

$$
\begin{gathered}
x_{1}=x \in C, \\
x_{n+1}=\alpha_{n} f\left(x_{n}\right)+\beta_{n} x_{n}+\gamma_{n} T_{n} x_{n}, \quad n \geq 1 .
\end{gathered}
$$

Suppose that $\left\{T_{n}\right\}$ satisfies the AKTT-condition. Let $T$ be a mapping of $C$ into itself defined by $T z=$ $\lim _{n \rightarrow \infty} T_{n} z$ for all $z \in C$ and suppose that $F(T)=\bigcap_{n=1}^{\infty} F\left(T_{n}\right)$. Then the sequence $\left\{x_{n}\right\}$ converges strongly to $\tilde{x}$ which solves the variational inequality:

$$
\left\langle(I-f) \tilde{x}, J_{\varphi}(\tilde{x}-z)\right\rangle \leq 0, \quad z \in F(T) .
$$

Proof. Rewrite the iterative sequence (3.26) as follows:

$$
x_{n+1}=\alpha_{n} f\left(x_{n}\right)+\beta_{n}^{\prime} x_{n}+\gamma_{n}^{\prime} S_{n} x_{n}, \quad n \geq 1,
$$

where $\beta_{n}^{\prime}=\beta_{n}-\left(\gamma_{n} / \xi\right)(1-\xi), \gamma_{n}^{\prime}=\gamma_{n} / \xi$ and $S_{n}:=(1-\xi) I+\xi T_{n}, I$ is the identity mapping. By Lemma 2.1, $S_{n}$ is nonexpansive such that $F\left(S_{n}\right)=F\left(T_{n}\right)$ for all $n \in \mathbb{N}$. Taking any $q \in$ $\bigcap_{n=1}^{\infty} F\left(T_{n}\right)$, from (3.28), it implies that

$$
\begin{aligned}
\left\|x_{n+1}-q\right\| & \leq \alpha_{n}\left\|f\left(x_{n}\right)-q\right\|+\beta_{n}^{\prime}\left\|x_{n}-q\right\|+\gamma_{n}^{\prime}\left\|S_{n} x_{n}-q\right\| \\
& \leq \alpha_{n} k\left\|x_{n}-q\right\|+\alpha_{n}\|f(q)-q\|+\left(1-\alpha_{n}\right)\left\|x_{n}-q\right\| \\
& =\alpha_{n}(1-k) \frac{1}{1-k}\|f(q)-q\|+\left(1-\alpha_{n}(1-k)\right)\left\|x_{n}-q\right\| \\
& \leq \max \left\{\left\|x_{1}-q\right\|, \frac{1}{1-k}\|f(q)-q\|\right\} .
\end{aligned}
$$


Therefore, the sequence $\left\{x_{n}\right\}$ is bounded, and so are the sequences $\left\{f\left(x_{n}\right)\right\},\left\{S_{n} x_{n}\right\}$. Since $S_{n} x_{n}=\left(1-\xi_{n}\right) x_{n}+\xi_{n} T_{n} x_{n}$ and lim inf $\xi_{n}>0$, we know that $\left\{T_{n} x_{n}\right\}$ is bounded. We note that for any bounded subset $B$ of $C$,

$$
\begin{aligned}
\sup _{z \in B}\left\|S_{n+1} z-S_{n} z\right\| & =\sup _{z \in B}\left[\left\|\left(\left(1-\xi_{n+1}\right) z+\xi_{n+1} T_{n+1} z\right)-\left(\left(1-\xi_{n}\right) z+\xi_{n} T_{n} z\right)\right\|\right] \\
& \leq\left|\xi_{n+1}-\xi_{n}\right| \sup _{z \in B}\|z\|+\xi_{n+1} \sup _{z \in B}\left\|T_{n+1} z-T_{n} z\right\|+\left|\xi_{n+1}-\xi_{n}\right| \sup _{z \in B}\left\|T_{n} z\right\| \\
& =\left|\xi_{n+1}-\xi_{n}\right| \sup _{z \in B}(\|z\|+\|T z\|)+\xi_{n+1} \sup _{z \in B}\left\|T_{n+1} z-T_{n} z\right\| .
\end{aligned}
$$

From $\sum_{n=1}^{\infty}\left|\xi_{n+1}-\xi_{n}\right|<\infty$ and $\left\{T_{n}\right\}$ satisfing AKTT-condition, we obtain that

$$
\sum_{n=1}^{\infty} \sup _{z \in B}\left\|S_{n+1} z-S_{n} z\right\|<\infty
$$

that is, the sequence $\left\{S_{n}\right\}$ satisfies AKTT-condition. Applying Lemma 2.6, we can take the mapping $S: C \rightarrow C$ defined by

$$
S z=\lim _{n \rightarrow \infty} S_{n} z, \quad \forall z \in C
$$

Moreover, we have $S$ is nonexpansive and

$$
S z=\lim _{n \rightarrow \infty} S_{n} z=\lim _{n \rightarrow \infty}\left(\left(1-\xi_{n}\right) z+\xi_{n} T_{n} z\right)=(1-\xi) z+\xi T z
$$

It is easy to see that $F(S)=F(T)$. Hence $F(S)=\bigcap_{n=1}^{\infty} F\left(T_{n}\right)=\bigcap_{n=1}^{\infty} F\left(S_{n}\right)$. The iterative sequence (3.28) can be expressed as follows:

$$
x_{n+1}=\beta_{n}^{\prime} x_{n}+\left(1-\beta_{n}^{\prime}\right) y_{n}
$$

where

$$
y_{n}=\frac{\alpha_{n}}{1-\beta_{n}^{\prime}} f\left(x_{n}\right)+\frac{\gamma_{n}^{\prime}}{1-\beta_{n}^{\prime}} S_{n} x_{n}
$$


We estimate from (3.35)

$$
\begin{aligned}
& \left\|y_{n+1}-y_{n}\right\|=\left\|\frac{\alpha_{n+1}}{1-\beta_{n+1}^{\prime}} f\left(x_{n+1}\right)+\frac{\gamma_{n+1}^{\prime}}{1-\beta_{n+1}^{\prime}} S_{n+1} x_{n+1}-\frac{\alpha_{n}}{1-\beta_{n}^{\prime}} f\left(x_{n}\right)+\frac{\gamma_{n}^{\prime}}{1-\beta_{n}^{\prime}} S_{n} x_{n}\right\| \\
& \leq \frac{\alpha_{n+1}}{1-\beta_{n+1}^{\prime}} k\left\|x_{n+1}-x_{n}\right\|+\frac{\gamma_{n+1}^{\prime}}{1-\beta_{n+1}^{\prime}}\left\|S_{n+1} x_{n+1}-S_{n} x_{n}\right\| \\
& +\left|\frac{\alpha_{n+1}}{1-\beta_{n+1}^{\prime}}-\frac{\alpha_{n}}{1-\beta_{n}^{\prime}}\right|\left\|f\left(x_{n}\right)-S_{n} x_{n}\right\| \\
& \leq \frac{\alpha_{n+1}}{1-\beta_{n+1}^{\prime}} k\left\|x_{n+1}-x_{n}\right\|+\frac{\gamma_{n+1}^{\prime}}{1-\beta_{n+1}^{\prime}}\left[\left\|S_{n+1} x_{n+1}-S_{n+1} x_{n}\right\|+\left\|S_{n+1} x_{n}-S_{n} x_{n}\right\|\right] \\
& +\left|\frac{\alpha_{n+1}}{1-\beta_{n+1}^{\prime}}-\frac{\alpha_{n}}{1-\beta_{n}^{\prime}}\right|\left\|f\left(x_{n}\right)-S_{n} x_{n}\right\| \\
& \leq \frac{\alpha_{n+1}}{1-\beta_{n+1}^{\prime}} k\left\|x_{n+1}-x_{n}\right\|+\frac{\gamma_{n+1}^{\prime}}{1-\beta_{n+1}^{\prime}}\left[\left\|x_{n+1}-x_{n}\right\|+\sup _{z \in\left\{x_{n}\right\}}\left\|S_{n+1} z-S_{n} z\right\|\right] \\
& +\left|\frac{\alpha_{n+1}}{1-\beta_{n+1}^{\prime}}-\frac{\alpha_{n}}{1-\beta_{n}^{\prime}}\right|\left\|f\left(x_{n}\right)-S_{n} x_{n}\right\| \text {. }
\end{aligned}
$$

Hence

$$
\begin{aligned}
\left\|y_{n+1}-y_{n}\right\|-\left\|x_{n+1}-x_{n}\right\| \leq & \frac{\alpha_{n+1}}{1-\beta_{n+1}^{\prime}} k\left\|x_{n+1}-x_{n}\right\|+\frac{\gamma_{n+1}^{\prime}}{1-\beta_{n+1}^{\prime}} \sup _{z \in\left\{x_{n}\right\}}\left\|S_{n+1} z-S_{n} z\right\| \\
& +\left|\frac{\alpha_{n+1}}{1-\beta_{n+1}^{\prime}}-\frac{\alpha_{n}}{1-\beta_{n}^{\prime}}\right|\left\|f\left(x_{n}\right)-S_{n} x_{n}\right\| .
\end{aligned}
$$

Since $\lim _{n \rightarrow \infty} \alpha_{n}=0$, and $\lim _{n \rightarrow \infty} \sup _{z \in\left\{x_{n}\right\}}\left\|S_{n+1} z-S_{n} z\right\|=0$, we have from (3.37) that

$$
\limsup _{n \rightarrow \infty}\left(\left\|y_{n+1}-y_{n}\right\|-\left\|x_{n+1}-x_{n}\right\|\right) \leq 0
$$

Hence, by Lemma 2.3, we obtain

$$
\lim _{n \rightarrow \infty}\left\|y_{n}-x_{n}\right\|=0
$$

From (3.35), we get

$$
\lim _{n \rightarrow \infty}\left\|y_{n}-S_{n} x_{n}\right\|=\lim _{n \rightarrow \infty} \frac{\alpha_{n}}{1-\beta_{n}^{\prime}}\left\|f\left(x_{n}\right)-S_{n} x_{n}\right\|=0,
$$


and so it follows from (3.39) and (3.40) that

$$
\lim _{n \rightarrow \infty}\left\|x_{n}-S_{n} x_{n}\right\|=0
$$

It follows from Lemma 2.6 and (3.41), we have

$$
\begin{aligned}
\left\|x_{n}-S x_{n}\right\| & \leq\left\|x_{n}-S_{n} x_{n}\right\|+\left\|S_{n} x_{n}-S x_{n}\right\| \\
& \leq\left\|x_{n}-S_{n} x_{n}\right\|+\sup \left\{\left\|S_{n} z-S z\right\|: z \in\left\{x_{n}\right\}\right\} \longrightarrow 0, \quad \text { as } n \longrightarrow \infty
\end{aligned}
$$

Since $S$ is a nonexpansive mapping, we have from Lemma 3.1 that the net $\left\{x_{t}\right\}$ generated by

$$
x_{t}=t f\left(x_{t}\right)+(1-t) S x
$$

converges strongly to $\tilde{x} \in F(S)$, as $t \rightarrow 0^{+}$. Next, we prove that

$$
\limsup _{n \rightarrow \infty}\left\langle f(\tilde{x})-\tilde{x}, J_{\varphi}\left(x_{n}-\tilde{x}\right)\right\rangle \leq 0
$$

Let $\left\{x_{n_{k}}\right\}$ be a subsequence of $\left\{x_{n}\right\}$ such that

$$
\lim _{k \rightarrow \infty}\left\langle f(\tilde{x})-\tilde{x}, J_{\varphi}\left(x_{n_{k}}-\tilde{x}\right)\right\rangle=\limsup _{n \rightarrow \infty}\left\langle f(\tilde{x})-\tilde{x}, J_{\varphi}\left(x_{n}-\tilde{x}\right)\right\rangle
$$

If follows from reflexivity of $E$ and the boundedness of sequence $\left\{x_{n_{k}}\right\}$ that there exists $\left\{x_{n_{k_{k}}}\right\}$ which is a subsequence of $\left\{x_{n_{k}}\right\}$ converging weakly to $w \in C$ as $i \rightarrow \infty$. Since $J_{\varphi}$ is weakly continuous, we have by Lemma 2.8 that

$$
\limsup _{i \rightarrow \infty} \Phi\left(\left\|x_{n_{k_{i}}}-x\right\|\right)=\underset{i \rightarrow \infty}{\limsup } \Phi\left(\left\|x_{n_{k_{i}}}-w\right\|\right)+\Phi(\|x-w\|), \quad \forall x \in E .
$$

Let

$$
H(x)=\limsup _{i \rightarrow \infty} \Phi\left(\left\|x_{n_{k_{i}}}-x\right\|\right), \quad \forall x \in E
$$

It follows that

$$
H(x)=H(w)+\Phi(\|x-w\|), \quad \forall x \in E .
$$

From (3.42), we obtain

$$
\begin{aligned}
H(S w) & =\limsup _{i \rightarrow \infty} \Phi\left(\left\|x_{n_{k_{i}}}-S w\right\|\right)=\underset{i \rightarrow \infty}{\limsup } \Phi\left(\left\|S x_{n_{k_{i}}}-S w\right\|\right) \\
& \leq \limsup _{i \rightarrow \infty} \Phi\left(\left\|x_{n_{k_{i}}}-w\right\|\right)=H(w) .
\end{aligned}
$$


Fixed Point Theory and Applications

On the other hand, however,

$$
H(S w)=H(w)+\Phi(\|S(w)-w\|)
$$

It follows from (3.49) and (3.50) that

$$
\Phi(\|S(w)-w\|)=H(S w)-H(w) \leq 0
$$

This implies that $S w=w$, that is, $w \in F(S)=F(T)$. Since the duality map $J_{\varphi}$ is single-valued and weakly continuous, we get that

$$
\begin{aligned}
\limsup _{n \rightarrow \infty}\left\langle f(\tilde{x})-\tilde{x}, J_{\varphi}\left(x_{n}-\tilde{x}\right)\right\rangle & =\lim _{k \rightarrow \infty}\left\langle f(\tilde{x})-\tilde{x}, J_{\varphi}\left(x_{n_{k}}-\tilde{x}\right)\right\rangle \\
& =\lim _{i \rightarrow \infty}\left\langle f(\tilde{x})-\tilde{x}, J_{\varphi}\left(x_{n_{k_{i}}}-\tilde{x}\right)\right\rangle \\
& =\left\langle(I-f) \tilde{x}, J_{\varphi}(\tilde{x}-w)\right\rangle \leq 0
\end{aligned}
$$

as required. Finally, we show that $x_{n} \rightarrow \tilde{x}$ as $n \rightarrow \infty$.

$$
\begin{aligned}
\Phi\left(\left\|x_{n+1}-\tilde{x}\right\|\right)= & \Phi\left(\left\|\alpha_{n}\left(f\left(x_{n}\right)-f(\tilde{x})\right)+\beta_{n}^{\prime}\left(x_{n}-\tilde{x}\right)+\gamma_{n}^{\prime}\left(S_{n} x_{n}-\tilde{x}\right)+\alpha_{n}(f(\tilde{x})-\tilde{x})\right\|\right) \\
\leq & \Phi\left(\left\|\alpha_{n}\left(f\left(x_{n}\right)-f(\tilde{x})\right)+\beta_{n}^{\prime}\left(x_{n}-\tilde{x}\right)+\gamma_{n}^{\prime}\left(S_{n} x_{n}-\tilde{x}\right)\right\|\right) \\
& +\alpha_{n}\left\langle f(\tilde{x})-\tilde{x}, J_{\varphi}\left(x_{n+1}-\tilde{x}\right)\right\rangle \\
\leq & \Phi\left(\alpha_{n} k\left\|x_{n}-\tilde{x}\right\|+\beta_{n}^{\prime}\left\|x_{n}-\tilde{x}\right\|+\gamma_{n}^{\prime}\left\|x_{n}-\tilde{x}\right\|\right) \\
& +\alpha_{n}\left\langle f(\tilde{x})-\tilde{x}, J_{\varphi}\left(x_{n+1}-\tilde{x}\right)\right\rangle \\
= & \Phi\left(\left(1-\alpha_{n}(1-k)\right)\left\|x_{n}-\tilde{x}\right\|\right)+\alpha_{n}\left\langle f(\tilde{x})-\tilde{x}, J_{\varphi}\left(x_{n+1}-\tilde{x}\right)\right\rangle \\
\leq & \left(1-\alpha_{n}(1-k)\right) \Phi\left(\left\|x_{n}-\tilde{x}\right\|\right)+\alpha_{n}\left\langle f(\tilde{x})-\tilde{x}, J_{\varphi}\left(x_{n+1}-\tilde{x}\right)\right\rangle .
\end{aligned}
$$

It follows that from condition (i) and (3.44) that

$$
\lim _{n \rightarrow \infty} \alpha_{n}=0, \quad \sum_{n=1}^{\infty} \alpha_{n}=\infty, \quad \limsup _{n \rightarrow \infty}\left\langle f(\tilde{x})-\tilde{x}, J_{\varphi}\left(x_{n+1}-\tilde{x}\right)\right\rangle \leq 0
$$

Apply Lemma 2.7 to (3.53) to conclude $\Phi\left(\left\|x_{n+1}-\tilde{x}\right\|\right) \rightarrow 0$ as $n \rightarrow \infty$; that is, $x_{n} \rightarrow \tilde{x}$ as $n \rightarrow \infty$. This completes the proof. results.

If $\left\{T_{n}: C \rightarrow C\right\}$ is a family of nonexpansive mappings, then we obtain the following

Corollary 3.3. Let E be a real p-uniformly convex Banach space with a weakly continuous duality mapping $J_{\varphi}$, and $C$ a nonempty closed convex subset of $E$. Let $\left\{T_{n}: C \rightarrow C\right\}$ be a family of 
nonexpansive mappings such that $\bigcap_{n=1}^{\infty} F\left(T_{n}\right) \neq \emptyset$. Let $f: C \rightarrow C$ be a $k$-contraction with $k \in(0,1)$. Assume that real sequences $\left\{\alpha_{n}\right\},\left\{\beta_{n}\right\}$ and $\left\{\gamma_{n}\right\}$ in $(0,1)$ satisfy the following conditions:

(i) $\alpha_{n}+\beta_{n}+\gamma_{n}=1$ for all $n \in \mathbb{N}$;

(ii) $\lim _{n \rightarrow \infty} \alpha_{n}=0$ and $\sum_{n=0}^{\infty} \alpha_{n}=+\infty$;

(iii) $0<\lim \inf _{n \rightarrow \infty} \gamma_{n} \leq \lim \sup _{n \rightarrow \infty} \gamma_{n}<1$.

Let $\left\{x_{n}\right\}$ be the sequence generated by the following:

$$
\begin{gathered}
x_{1}=x \in C, \\
x_{n+1}=\alpha_{n} f\left(x_{n}\right)+\beta_{n} x_{n}+\gamma_{n} T_{n} x_{n}, \quad n \geq 1 .
\end{gathered}
$$

Suppose that $\left\{T_{n}\right\}$ satisfies the AKTT-condition. Let $T$ be a mapping of $C$ into itself defined by $T z=$ $\lim _{n \rightarrow \infty} T_{n} z$ for all $z \in C$ and suppose that $F(T)=\bigcap_{n=1}^{\infty} F\left(T_{n}\right)$. Then the sequence $\left\{x_{n}\right\}$ converges strongly $\tilde{x}$ which solves the variational inequality:

$$
\left\langle(I-f) \tilde{x}, J_{\varphi}(\tilde{x}-z)\right\rangle \leq 0, \quad z \in F(T) .
$$

Corollary 3.4. Let E be a real p-uniformly convex Banach space with a weakly continuous duality mapping $J_{\varphi}$, and $C$ a nonempty closed convex subset of $E$. Let $T: C \rightarrow C$ be a $\lambda$-strict pseudocontraction with respect to $p, \lambda \in\left[0, \min \left\{1,2^{-(p-2)} c_{p}\right\}\right)$ and $F(T) \neq \emptyset$. Let $f: C \rightarrow C$ be a $k$ contraction with $k \in(0,1)$. Assume that real sequences $\left\{\alpha_{n}\right\},\left\{\beta_{n}\right\}$ and $\left\{\gamma_{n}\right\}$ in $(0,1)$ satisfy the following conditions:

(i) $\alpha_{n}+\beta_{n}+\gamma_{n}=1$ for all $n \in \mathbb{N}$;

(ii) $\lim _{n \rightarrow \infty} \alpha_{n}=0$ and $\sum_{n=0}^{\infty} \alpha_{n}=+\infty$;

(iii) $0<\lim \inf _{n \rightarrow \infty} \gamma_{n} \leq \lim \sup _{n \rightarrow \infty} \gamma_{n}<\xi$, where $\xi=1-2^{p-2} \lambda c_{p}^{-1}$.

Let $\left\{x_{n}\right\}$ be the sequence generated by the following

$$
\begin{gathered}
x_{1}=x \in C, \\
x_{n+1}=\alpha_{n} f\left(x_{n}\right)+\beta_{n} x_{n}+\gamma_{n} T x_{n}, \quad n \geq 1 .
\end{gathered}
$$

Then the sequence $\left\{x_{n}\right\}$ converges strongly to $\tilde{x}$ which solves the following variational inequality:

$$
\left\langle(I-f) \tilde{x}, J_{\varphi}(\tilde{x}-z)\right\rangle \leq 0, \quad z \in F(T)
$$

Theorem 3.5. Let E be a real p-uniformly convex Banach space with uniformly Gâteaux differentiable norm, and $C$ a nonempty closed convex subset of $E$ which has the fixed point property for nonexpansive mappings. Let $\left\{T_{n}: C \rightarrow C\right\}$ be a family of uniformly $\lambda$-strict pseudo-contractions with respect to 
$p, \lambda \in\left[0, \min \left\{1,2^{-(p-2)} c_{p}\right\}\right)$ and $\bigcap_{n=1}^{\infty} F\left(T_{n}\right) \neq \emptyset$. Let $f: C \rightarrow C$ be a $k$-contraction with $k \in(0,1)$. Assume that real sequences $\left\{\alpha_{n}\right\},\left\{\beta_{n}\right\}$ and $\left\{\gamma_{n}\right\}$ in $(0,1)$ satisfy the following conditions:

(i) $\alpha_{n}+\beta_{n}+\gamma_{n}=1$ for all $n \in \mathbb{N}$;

(ii) $\lim _{n \rightarrow \infty} \alpha_{n}=0$ and $\sum_{n=0}^{\infty} \alpha_{n}=+\infty$;

(iii) $0<\lim \inf _{n \rightarrow \infty} \gamma_{n} \leq \lim \sup _{n \rightarrow \infty} \gamma_{n}<\xi$, where $\xi=1-2^{p-2} \lambda c_{p}^{-1}$.

Let $\left\{x_{n}\right\}$ be the sequence generated by the following:

$$
\begin{gathered}
x_{1}=x \in C, \\
x_{n+1}=\alpha_{n} f\left(x_{n}\right)+\beta_{n} x_{n}+\gamma_{n} T_{n} x_{n}, \quad n \geq 1 .
\end{gathered}
$$

Suppose that $\left\{T_{n}\right\}$ satisfies the AKTT-condition. Let $T$ be a mapping of $C$ into itself defined by $T z=$ $\lim _{n \rightarrow \infty} T_{n} z$ for all $z \in C$ and suppose that $F(T)=\bigcap_{n=1}^{\infty} F\left(T_{n}\right)$. Then the sequence $\left\{x_{n}\right\}$ converges strongly to a common fixed point $\tilde{x}$ of $\left\{T_{n}\right\}$.

Proof. It follows from the same argumentation as Theorem 3.2 that $\left\{x_{n}\right\}$ is bounded and $\lim _{n \rightarrow \infty}\left\|x_{n}-S x_{n}\right\|=0$, where $S$ is a nonexpansive mapping defined by (3.32). From Lemma 2.2 that the net $\left\{x_{t}\right\}$ generated by $x_{t}=t f\left(x_{t}\right)+(1-t) S x_{t}$ converges strongly to $\tilde{x} \in F(S)=F(T)$, as $t \rightarrow 0^{+}$. Obviously,

$$
x_{t}-x_{n}=(1-t)\left(S x_{t}-x_{n}\right)+t\left(f\left(x_{t}\right)-x_{n}\right) .
$$

In view of Lemma 2.8 , we calculate

$$
\begin{aligned}
\left\|x_{t}-x_{n}\right\|^{2} \leq & (1-t)^{2}\left\|S x_{t}-x_{n}\right\|^{2}+2 t\left\langle f\left(x_{t}\right)-x_{n}, J\left(x_{t}-x_{n}\right)\right\rangle \\
\leq & \left(1-2 t+t^{2}\right)\left(\left\|x_{t}-x_{n}\right\|+\left\|S x_{n}-x_{n}\right\|\right)^{2} \\
& +2 t\left\langle f\left(x_{t}\right)-x_{t}, J\left(x_{t}-x_{n}\right)\right\rangle+2 t\left\|x_{t}-x_{n}\right\|^{2}
\end{aligned}
$$

and therefore

$$
\left\langle f\left(x_{t}\right)-x_{t}, J\left(x_{n}-x_{t}\right)\right\rangle \leq \frac{t}{2}\left\|x_{t}-x_{n}\right\|^{2}+\frac{(1+t)^{2}\left\|x_{n}-S x_{n}\right\|}{2 t}\left(2\left\|x_{t}-x_{n}\right\|+\left\|x_{n}-S x_{n}\right\|\right) .
$$

Since $\left\{x_{n}\right\},\left\{x_{t}\right\}$ and $\left\{S x_{n}\right\}$ are bounded and $\lim _{n \rightarrow \infty}\left(\left\|x_{n}-S x_{n}\right\| / 2 t\right)=0$, we obtain

$$
\limsup _{n \rightarrow \infty}\left\langle f\left(x_{t}\right)-x_{t}, J\left(x_{n}-x_{t}\right)\right\rangle \leq \frac{t}{2} M,
$$

where $M=\sup _{n \geq 1, t \in(0,1)}\left\{\left\|x_{t}-x_{n}\right\|^{2}\right\}$. We also know that

$$
\begin{aligned}
\left\langle f(\tilde{x})-\tilde{x}, J\left(x_{n}-\tilde{x}\right)\right\rangle= & \left\langle f\left(x_{t}\right)-x_{t}, J\left(x_{n}-x_{t}\right)\right\rangle+\left\langle f(\tilde{x})-f\left(x_{t}\right)+x_{t}-\tilde{x}, J\left(x_{n}-x_{t}\right)\right\rangle \\
& +\left\langle f(\tilde{x})-\tilde{x}, J\left(x_{n}-\tilde{x}\right)-J\left(x_{n}-x_{t}\right)\right\rangle .
\end{aligned}
$$


From the fact that $x_{t} \rightarrow \tilde{x} \in F(T)$, as $t \rightarrow 0,\left\{x_{n}\right\}$ is bounded and the duality mapping $J$ is norm-to-weak ${ }^{*}$ uniformly continuous on bounded subset of $E$, it follows that as $t \rightarrow 0$,

$$
\begin{array}{ll}
\left\langle f(\tilde{x})-\tilde{x}, J\left(x_{n}-\tilde{x}\right)-J\left(x_{n}-x_{t}\right)\right\rangle \longrightarrow 0, \quad \forall n \in \mathbb{N}, \\
\left\langle f(\tilde{x})-f\left(x_{t}\right)+x_{t}-\tilde{x}, J\left(x_{n}-x_{t}\right)\right\rangle \longrightarrow 0, \quad \forall n \in \mathbb{N} .
\end{array}
$$

Combining (3.63), (3.64) and two results mentioned above, we get

$$
\limsup _{n \rightarrow \infty}\left\langle f(\tilde{x})-\tilde{x}, J\left(x_{n}-\tilde{x}\right)\right\rangle \leq 0 .
$$

From (3.28) and Lemma 2.8, we get

$$
\begin{aligned}
\left\|x_{n+1}-\tilde{x}\right\|^{2} \leq & \left\|\alpha_{n}\left(f\left(x_{n}\right)-f(\tilde{x})\right)+\beta_{n}^{\prime}\left(x_{n}-\tilde{x}\right)+\gamma_{n}^{\prime}\left(S_{n} x_{n}-\tilde{x}\right)\right\|^{2} \\
& +2 \alpha_{n}\left\langle f(\tilde{x})-\tilde{x}, J\left(x_{n+1}-\tilde{x}\right)\right\rangle \\
\leq & \left(1-\alpha_{n}(1-k)\right)\left\|x_{n}-\tilde{x}\right\|^{2}+2 \alpha_{n}\left\langle f(\tilde{x})-\tilde{x}_{1} J\left(x_{n+1}-\tilde{x}\right)\right\rangle .
\end{aligned}
$$

Hence applying in Lemma 2.7 to (3.67), we conclude that $\lim _{n \rightarrow \infty}\left\|x_{n}-\tilde{x}\right\|=0$.

Corollary 3.6. Let E be a real p-uniformly convex Banach space with uniformly Gâteaux differentiable norm, and $C$ a nonempty closed convex subset of $E$ which has the fixed point property for nonexpansive mappings. Let $\left\{T_{n}: C \rightarrow C\right\}$ be a family of nonexpansive mappings such that $\bigcap_{n=1}^{\infty} F\left(T_{n}\right) \neq \emptyset$. Let $f: C \rightarrow C$ be a $k$-contraction with $k \in(0,1)$. Assume that real sequences $\left\{\alpha_{n}\right\},\left\{\beta_{n}\right\}$ and $\left\{\gamma_{n}\right\}$ in $(0,1)$ satisfy the following conditions:

(i) $\alpha_{n}+\beta_{n}+\gamma_{n}=1$ for all $n \in \mathbb{N}$;

(ii) $\lim _{n \rightarrow \infty} \alpha_{n}=0$ and $\sum_{n=0}^{\infty} \alpha_{n}=+\infty$;

(iii) $0<\lim \inf _{n \rightarrow \infty} \gamma_{n} \leq \lim \sup _{n \rightarrow \infty} \gamma_{n}<1$.

Let $\left\{x_{n}\right\}$ be the sequence generated by the following:

$$
\begin{gathered}
x_{1}=x \in C, \\
x_{n+1}=\alpha_{n} f\left(x_{n}\right)+\beta_{n} x_{n}+\gamma_{n} T_{n} x_{n}, \quad n \geq 1 .
\end{gathered}
$$

Suppose that $\left\{T_{n}\right\}$ satisfies the AKTT-condition. Let $T$ be a mapping of $C$ into itself defined by $T z=$ $\lim _{n \rightarrow \infty} T_{n} z$ for all $z \in C$ and suppose that $F(T)=\bigcap_{n=1}^{\infty} F\left(T_{n}\right)$. Then the sequence $\left\{x_{n}\right\}$ converges strongly to a common fixed point $\tilde{x}$ of $\left\{T_{n}\right\}$.

Corollary 3.7. Let E be a real p-uniformly convex Banach space with uniformly Gâteaux differentiable norm, and $C$ a nonempty closed convex subset of $E$ which has the fixed point property for nonexpansive mappings. Let $T: C \rightarrow C$ be a $\lambda$-strict pseudo-contractions with respect to 
$p, \lambda \in\left[0, \min \left\{1,2^{-(p-2)} c_{p}\right\}\right)$ and $F(T) \neq \emptyset$. Let $f: C \rightarrow C$ be a $k$-contraction with $k \in(0,1)$. Assume that real sequences $\left\{\alpha_{n}\right\},\left\{\beta_{n}\right\}$ and $\left\{\gamma_{n}\right\}$ in $(0,1)$ satisfy the following conditions:

(i) $\alpha_{n}+\beta_{n}+\gamma_{n}=1$ for all $n \in \mathbb{N}$;

(ii) $\lim _{n \rightarrow \infty} \alpha_{n}=0$ and $\sum_{n=0}^{\infty} \alpha_{n}=+\infty$;

(iii) $0<\lim _{\inf _{n \rightarrow \infty}} \gamma_{n} \leq \lim \sup _{n \rightarrow \infty} \gamma_{n}<\xi$, where $\xi=1-2^{p-2} \lambda c_{p}^{-1}$.

Let $\left\{x_{n}\right\}$ be the sequence generated by the following:

$$
\begin{gathered}
x_{1}=x \in C, \\
x_{n+1}=\alpha_{n} f\left(x_{n}\right)+\beta_{n} x_{n}+\gamma_{n} T x_{n}, \quad n \geq 1 .
\end{gathered}
$$

Then the sequence $\left\{x_{n}\right\}$ converges strongly to a common fixed point $\tilde{x}$ of $\left\{T_{n}\right\}$.

\section{Some Applications for Accretive Operators}

We consider the problem of finding a zero of an accretive operator. An operator $\Psi \subset E \times E$ is said to be accretive if for each $\left(x_{1}, y_{1}\right)$ and $\left(x_{2}, y_{2}\right) \in \Psi$, there exists $j \in J\left(x_{1}-x_{2}\right)$ such that $\left\langle y_{1}-\right.$ $\left.y_{2}, j\right\rangle \geq 0$. An accretive operator $\Psi$ is said to satisfy the range condition if $\overline{D(\Psi)} \subset R(I+\lambda \Psi)$ for all $\lambda>0$, where $D(\Psi)$ is the domain of $\Psi, I$ is the identity mapping on $E, R(I+\lambda \Psi)$ is the range of $I+\lambda \Psi$, and $\overline{D(\Psi)}$ is the closure of $D(\Psi)$. If $\Psi$ is an accretive operator which satisfies the range condition, then we can define, for each $\lambda>0$, a mapping $J_{\lambda}: R(I+\lambda \Psi) \rightarrow D(\Psi)$ by $J_{\lambda}=(I+\lambda \Psi)^{-1}$, which is called the resolvent of $\Psi$. We know that $J_{\lambda}$ is nonexpansive and $F\left(J_{\lambda}\right)=\Psi^{-1}(0)$ for all $\lambda>0$. We also know the following [25]: For each $\lambda, \mu>0$ and $x \in R(I+\lambda \Psi) \cap R(I+\mu \Psi)$, it holds that

$$
\left\|J_{\lambda} x-J_{\mu} x\right\| \leq \frac{|\lambda-\mu|}{\lambda}\left\|x-J_{\lambda} x\right\|
$$

By the proof of Theorem 4.3 in [3], we have the following lemma.

Lemma 4.1. Let $E$ be a Banach space and $C$ a nonempty closed convex subset of $E$. Let $\Psi \subseteq E \times E$ be an accretive operator such that $\Psi^{-1} 0 \neq \emptyset$ and $\overline{D(\Psi)} \subset C \subset \bigcap_{\lambda>0} R(I+\lambda \Psi)$. Suppose that $\left\{\lambda_{n}\right\}$ is a sequence of $(0, \infty)$ such that $\inf \left\{\lambda_{n}: n \in \mathbb{N}\right\}>0$ and $\sum_{n=1}^{\infty}\left|\lambda_{n+1}-\lambda_{n}\right|<\infty$. Then

(i) The sequence $\left\{J_{\lambda_{n}}\right\}$ satisfies the AKTT-condition.

(ii) $\lim _{n \rightarrow \infty} J_{\lambda_{n}} z=J_{\lambda} z$ for all $z \in C$ and $F\left(J_{\lambda}\right)=\bigcap_{n=1}^{\infty} F\left(J_{\lambda_{n}}\right)$ where $\lambda_{n} \rightarrow \lambda$ as $n \rightarrow \infty$.

By Corollary 3.3, we obtain the following result.

Theorem 4.2. Let E be a real p-uniformly convex Banach space with a weakly continuous duality mapping $J_{\varphi}$, and $C$ a nonempty closed convex subset of $E$. Let $\Psi$ is an $m$-accretive operator in $E$ such 
that $\Psi^{-1} 0 \neq \emptyset$. Let $f: C \rightarrow C$ be a $k$-contraction with $k \in(0,1)$. Assume that real sequences $\left\{\alpha_{n}\right\}$, $\left\{\beta_{n}\right\}$ and $\left\{\gamma_{n}\right\}$ in $(0,1)$ satisfy the following conditions:

(i) $\alpha_{n}+\beta_{n}+\gamma_{n}=1$ for all $n \in \mathbb{N}$;

(ii) $\lim _{n \rightarrow \infty} \alpha_{n}=0$ and $\sum_{n=0}^{\infty} \alpha_{n}=+\infty$;

(iii) $0<\lim \inf _{n \rightarrow \infty} \gamma_{n} \leq \lim \sup _{n \rightarrow \infty} \gamma_{n}<1$;

(iv) $\left\{\lambda_{n}\right\}$ is a sequence of $(0, \infty)$ such that $\inf \left\{\lambda_{n}: n \in \mathbb{N}\right\}>0$ and $\sum_{n=1}^{\infty}\left|\lambda_{n+1}-\lambda_{n}\right|<\infty$.

Let $\left\{x_{n}\right\}$ be the sequence generated by the following:

$$
\begin{gathered}
x_{1}=x \in C, \\
x_{n+1}=\alpha_{n} f\left(x_{n}\right)+\beta_{n} x_{n}+\gamma_{n} J_{\lambda_{n}} x_{n}, \quad n \geq 1 .
\end{gathered}
$$

Then the sequence $\left\{x_{n}\right\}$ converges strongly $\tilde{x}$ which solves the following variational inequality:

$$
\left\langle(I-f) \tilde{x}, J_{\varphi}(\tilde{x}-z)\right\rangle \leq 0, \quad z \in F\left(J_{\lambda}\right) .
$$

By Corollary 3.6, we obtain the following result.

Theorem 4.3. Let E be a real p-uniformly convex Banach space with uniformly Gâteaux differentiable norm, and $C$ a nonempty closed convex subset of $E$. Let $\Psi$ is an $m$-accretive operator in $E$ such that $\Psi^{-1} 0 \neq \emptyset$. Let $f: C \rightarrow C$ be a $k$-contraction with $k \in(0,1)$. Assume that real sequences $\left\{\alpha_{n}\right\},\left\{\beta_{n}\right\}$ and $\left\{\gamma_{n}\right\}$ in $(0,1)$ satisfy the following conditions:

(i) $\alpha_{n}+\beta_{n}+\gamma_{n}=1$ for all $n \in \mathbb{N}$;

(ii) $\lim _{n \rightarrow \infty} \alpha_{n}=0$ and $\sum_{n=0}^{\infty} \alpha_{n}=+\infty$;

(iii) $0<\lim \inf _{n \rightarrow \infty} \gamma_{n} \leq \lim \sup _{n \rightarrow \infty} \gamma_{n}<1$;

(iv) $\left\{\lambda_{n}\right\}$ is a sequence of $(0, \infty)$ such that $\inf \left\{\lambda_{n}: n \in \mathbb{N}\right\}>0$ and $\sum_{n=1}^{\infty}\left|\lambda_{n+1}-\lambda_{n}\right|<\infty$.

Let $\left\{x_{n}\right\}$ be the sequence generated by the following:

$$
\begin{gathered}
x_{1}=x \in C, \\
x_{n+1}=\alpha_{n} f\left(x_{n}\right)+\beta_{n} x_{n}+\gamma_{n} J_{\lambda_{n}} x_{n}, \quad n \geq 1 .
\end{gathered}
$$

Then the sequence $\left\{x_{n}\right\}$ converges strongly $\tilde{x}$ in $\Psi^{-1} 0$.

\section{Acknowledgments}

The first author is supported by the Thailand Research Fund under Grant TRG5280011 and the second author is supported by grant from the program of Strategic Scholarships for Frontier Research Network for the Ph.D. Program Thai Doctoral degree from the Office of the Higher Education Commission, Thailand. 


\section{References}

[1] F. E. Browder and W. V. Petryshyn, "Construction of fixed points of nonlinear mappings in Hilbert space," Journal of Mathematical Analysis and Applications, vol. 20, pp. 197-228, 1967.

[2] B. Halpern, "Fixed points of nonexpanding maps," Bulletin of the American Mathematical Society, vol. 73, pp. 957-961, 1967.

[3] K. Aoyama, Y. Kimura, W. Takahashi, and M. Toyoda, "Approximation of common fixed points of a countable family of nonexpansive mappings in a Banach space," Nonlinear Analysis: Theory, Methods $\mathcal{E}$ Applications, vol. 67, no. 8, pp. 2350-2360, 2007.

[4] Y. Song and Y. Zheng, "Strong convergence of iteration algorithms for a countable family of nonexpansive mappings," Nonlinear Analysis: Theory, Methods \& Applications, vol. 71, no. 7-8, pp. 30723082, 2009.

[5] J. S. Jung, "Iterative approaches to common fixed points of nonexpansive mappings in Banach spaces," Journal of Mathematical Analysis and Applications, vol. 302, no. 2, pp. 509-520, 2005.

[6] J. G. O'Hara, P. Pillay, and H.-K. Xu, "Iterative approaches to finding nearest common fixed points of nonexpansive mappings in Hilbert spaces," Nonlinear Analysis: Theory, Methods \& Applications, vol. 54, no. 8, pp. 1417-1426, 2003.

[7] J. G. O'Hara, P. Pillay, and H.-K. Xu, "Iterative approaches to convex feasibility problems in Banach spaces," Nonlinear Analysis: Theory, Methods E Applications, vol. 64, no. 9, pp. 2022-2042, 2006.

[8] R. Wangkeeree, "An iterative approximation method for a countable family of nonexpansive mappings in Hilbert spaces," Bulletin of the Malaysian Mathematical Sciences Society 2, vol. 32, no. 3, pp. 313-326, 2009.

[9] R. Wangkeeree and R. Wangkeeree, "Strong convergence of the iterative scheme based on the extragradient method for mixed equilibrium problems and fixed point problems of an infinite family of nonexpansive mappings," Nonlinear Analysis: Hybrid Systems, vol. 3, no. 4, pp. 719-733, 2009.

[10] R. Wangkeeree and U. Kamraksa, "A general iterative method for solving the variational inequality problem and fixed point problem of an infinite family of nonexpansive mappings in Hilbert spaces," Fixed Point Theory and Applications, vol. 2009, Article ID 369215, 23 pages, 2009.

[11] L.-G. Hu and J.-P. Wang, "Mann iteration of weak convergence theorems in Banach space," Acta Mathematicae Applicatae Sinica. English Series, vol. 25, no. 2, pp. 217-224, 2009.

[12] G. Marino and H.-K. Xu, "Weak and strong convergence theorems for strict pseudo-contractions in Hilbert spaces," Journal of Mathematical Analysis and Applications, vol. 329, no. 1, pp. 336-346, 2007.

[13] H. Zhou, "Convergence theorems of fixed points for Lipschitz pseudo-contractions in Hilbert spaces," Journal of Mathematical Analysis and Applications, vol. 343, no. 1, pp. 546-556, 2008.

[14] S. Reich, "Weak convergence theorems for nonexpansive mappings in Banach spaces," Journal of Mathematical Analysis and Applications, vol. 67, no. 2, pp. 274-276, 1979.

[15] L. G. Hu, "Theorems of strong convergence of mixed iterative methods for obtaining strict pseudocontractions in Banach spaces," Applied Mathematics Letters, vol. 23, no. 7, pp. 791-795, 2010.

[16] W. Takahashi, Nonlinear Functional Analysis: Fixed Point Theory and Its Application, Yokohama Publishers, Yokohama, Japan, 2000.

[17] R. E. Megginson, An Introduction to Banach Space Theory, vol. 183 of Graduate Texts in Mathematics, Springer, New York, NY, USA, 1998.

[18] H. K. Xu, "Inequalities in Banach spaces with applications," Nonlinear Analysis: Theory, Methods $\mathcal{E}$ Applications, vol. 16, no. 12, pp. 1127-1138, 1991.

[19] R. Chen and H. He, "Viscosity approximation of common fixed points of nonexpansive semigroups in Banach space," Applied Mathematics Letters, vol. 20, no. 7, pp. 751-757, 2007.

[20] H.-K. Xu, "Viscosity approximation methods for nonexpansive mappings," Journal of Mathematical Analysis and Applications, vol. 298, no. 1, pp. 279-291, 2004.

[21] T. Suzuki, "Strong convergence theorems for infinite families of nonexpansive mappings in general Banach spaces," Fixed Point Theory and Applications, vol. 2005, no. 1, pp. 103-123, 2005.

[22] H.-K. Xu, "Iterative algorithms for nonlinear operators," Journal of the London Mathematical Society 2, vol. 66, no. 1, pp. 240-256, 2002.

[23] F. E. Browder, "Convergence theorems for sequences of nonlinear operators in Banach spaces," Mathematische Zeitschrift, vol. 100, pp. 201-225, 1967.

[24] T.-C. Lim and H. K. Xu, "Fixed point theorems for asymptotically nonexpansive mappings," Nonlinear Analysis: Theory, Methods \& Applications, vol. 22, no. 11, pp. 1345-1355, 1994.

[25] K. Eshita and W. Takahashi, "Approximating zero points of accretive operators in general Banach spaces," JP Journal of Fixed Point Theory and Applications, vol. 2, no. 2, pp. 105-116, 2007. 